\title{
Faculty Perceptions Of Student Credibility Based On Email Addresses
}

\author{
Jeffrey A. Livermore, University of Baltimore, USA \\ Linda S. Wiechowski, Walsh College, USA \\ Marla G. Scafe, Walsh College, USA
}

\begin{abstract}
The purpose of this study was to evaluate faculty perceptions of student credibility based on email addresses. The survey was conducted at an upper division business school in Michigan where all students have completed at least two years of college courses. The survey results show that a student's selection of an email address does influence the faculty's perception of their credibility. An email address that consists of a nickname reduces the faculty's perception of student credibility as well as the domain name of the email service used by the student The reduced credibility may have a negative impact on the faculty member's perception of the student.
\end{abstract}

Keywords: student credibility; email address; online pedagogy

\section{INTRODUCTION}

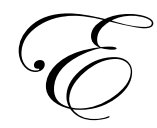

ducation is a constantly evolving discipline as teaching technologies and student expectations constantly change. The current body of college students expects technology to be part of their education and email is a widely accepted teaching and communication technology (Brunner, Yates, \& Adams, 2008). Many of the faculty members at Walsh College routinely use email to communicate with their students in both onground and online courses. The purpose of this study is to evaluate the faculty's perceptions of student credibility based on email addresses of students.

Email is an effective teaching tool because it allows faculty members to respond promptly to student concerns while creating a paper trail of their communication. Email is also an excellent tool for consistent communication with large groups of students (Brunner, Yates, \& Adams, 2008).

Faculty members that evaluate student work need to be careful of avoiding a "halo effect" when assessing student credibility. A study of medical students in the United Kingdom found that faculty members carried over positive impressions from one area of students' work to other areas of their work (Ottolini, Cuzzi, Tender, Cuddington, Focht, Patel \& Greenberg, 2007). This "halo effect" might impact online education more than onground education because faculty have fewer types of contact with students in online classes.

\section{LITERATURE REVIEW}

Several factors impact how students and faculty view the credibility of each other. Credibility has been found to have two major dimensions: competence and trustworthiness (Nadler \& Nadler, 2001). Credibility may play a role in how much interaction occurs between faculty and students. Email enables students and faculty to interact outside of the classroom. Several studies have found that increased amount of out of classroom contact increases the positive ratings that students give faculty in course evaluations (Nadler \& Nadler, 2001). Faculty that want to improve one student ratings should increase the amount of email communication that one has with students.

It is important that both faculty and students realize the importance of email names. The choice of a name can have either a positive or negative impact on impressions. A 1993 study found that the use of a given name has a 
greater impression of success than the use of a nickname (Mehrabian \& Piercy, 1993). A 2008 study found that the use of an email address can influence first impression, and first impressions are often lasting impressions ( Back, Schmukle \& Egloff, 2008). A 2009 study found that a faculty member's email address is an important factor in determining faculty credibility (Livermore, Scafe \& Wiechowski, 2010).

\section{METHOD}

In setting up this research project, the username and mail service provider were the independent variables and perceived credibility was the dependent variable. The following research hypotheses were evaluated:

H1: Faculty perception of student credibility will be impacted by the domain name used in the email address

H2: Faculty perception of student credibility will be impacted by the use of nicknames in the user name

To test these hypotheses, a survey was created with the Qualtrics tool and placed online for two months in 2010. Invitations to take the survey were sent to all of the full time and adjunct faculty at Walsh College. Walsh College is an upper division business school in the northern suburbs of Detroit. Students have all had at least two years of college courses and been exposed to a variety of faculty before enrolling at Walsh College.

To eliminate gender bias, the survey only referred to male names. Only the most popular male names were used in an attempt to eliminate name bias. The names used in this survey were a combination of the most popular first names and surnames according to two different sources. Based on data from the Social Security Administration, the three most popular first names in 2007 were Jacob, Michael, and Ethan (SSA 2008). The most popular surnames were once Smith, Johnson, and Brown (Barker, 1926).

\section{SURVEY}

The faculty responded to the following survey questions:

You received an email from Jacob Smith who has registered for one of your classes next semester. Based solely on his email address of MrBaseball@EDS.com, how credible do you feel this student is? Please rate Jacob Smith's credibility on a scale ranging from not credible to extremely credible (not credible, credible, extremely credible, no opinion).

You received an email from Michael Johnson who has registered for one of your classes next semester. Based solely on his email address of Michael.Johnson@ AOL.com how credible do you feel this student is? Please rate Michael Johnson's credibility on a scale ranging from not credible to extremely credible (not credible, credible, extremely credible, no opinion).

You received an email from Ethan Brown who has registered for one of your classes next semester. Based solely on his email address of Ethan.Brown@EDS.com, how credible do you feel this student is? Please rate Ethan Brown's credibility on a scale ranging from not credible to extremely credible (not credible, credible, extremely credible, no opinion).

You received an email from Jacob Brown who has registered for one of your classes next semester. Based solely on his email address of Jacob.Brown@mail.walshcollege.edu, how credible do you feel this student is? Please rate Jacob Brown's credibility on a scale ranging from not credible to extremely credible (not credible, credible, extremely credible, no opinion).

You received an email from Ethan Johnson who has registered for one of your classes next semester. Based solely on his email address of PartyMonster@ AOL.com , how credible do you feel this student is? Please rate Ethan Johnson's credibility on a scale ranging from not credible to extremely credible (not credible, credible, extremely credible, no opinion). 
You received an email from Michael Smith who has registered for one of your classes next semester. Based solely on his email address of PartyMonster@mail.walshcollege.edu, how credible do you feel this student is? Please rate Michael Smith's credibility on a scale ranging from not credible to extremely credible (not credible, credible, extremely credible, no opinion).

\section{RESULTS}

The survey respondents were mostly male, with 40 male respondents and 19 female respondents. Walsh relies heavily on adjunct members and has approximately three fourths of their classes taught by adjunct faculty members. The respondents reflect this, with 48 adjunct faculty members responding along with eleven full time faculty members. At the time of the survey, Walsh only had 16 full-time faculty members and over one hundred adjunct faculty. The faculty members had a range from 0 to 34 years of teaching experience. The median experience level was 8 years. The mean amount of experience was 9.456 years with a deviation of 8.077. While this represents a wide range of years of experience, this was somewhat expected given the wide variation in years of service to the college provided by adjunct faculty members who teach at a variety of higher education institutions.

Survey results were obtained for each scenario presented to Walsh College faculty and are as follows:

Table 1

Summarized Survey Results

\begin{tabular}{|l|c|c|c|c|c|}
\hline \multicolumn{1}{|c|}{ Email Account } & $\begin{array}{c}\text { Extremely } \\
\text { Credible }\end{array}$ & Credible & $\begin{array}{c}\text { Not } \\
\text { Credible }\end{array}$ & No Opinion & Total \\
\hline Full name at walshcollege.edu & 31 & 22 & 0 & 8 & 61 \\
\hline Full name at EDS.com & 18 & 32 & 2 & 9 & 61 \\
\hline Full name at aol.com & 15 & 36 & 1 & 10 & 62 \\
\hline Nickname at EDS.com & 0 & 29 & 20 & 13 & 62 \\
\hline Nickname at walshcollege.edu & 1 & 7 & 45 & 7 & 60 \\
\hline Nickname at aol.com & 0 & 10 & 43 & 7 & 60 \\
\hline
\end{tabular}

The detailed results for each question are as follows:

\section{Scenario one: Mr.Baseball@EDS.com.}

20 or $32 \%$ evaluated this email address as not credible, 29 or $47 \%$ thought it was credible. None of the respondents thought it was extremely credible and $13(21 \%)$ had no opinion. More faculty felt that this email address was credible compared with those that found it to be not credible. A Chi-square Goodness of Fit test showed a significant difference in credibility rankings (Chi-sq= 28.9677, $\mathrm{p}=.000)$.

Scenario Two: Michael.Johnson@aol.com

One or $2 \%$ evaluated this email address as not credible as opposed to 36 or $58 \%$ who viewed this address as credible. Fifteen responded that it was extremely credible and $10(16 \%)$ had no opinion. Almost $82 \%$ of the respondents viewed this email address as credible or extremely credible as opposed to $47 \%$ for the first scenario. More faculty felt that this email address was credible compared with those that found it to be not credible. A Chisquare Goodness of Fit test showed a significant difference in credibility rankings (Chi-sq= 42.6452, p=.000).

Scenario Three: Ethan.Brown@EDS.com

Only 2 respondents (3\%) evaluated this email address as not credible. $32(52 \%)$ thought this person was credible and $18(30 \%)$ thought he was an extremely credible source. Nine respondents had no opinion. More faculty felt that this email address was credible compared with those that found it to be not credible. A Chi-square Goodness of Fit test showed a significant difference in credibility rankings (Chi-sq= 32.9672, p=.000). 
Scenario Four: Jacob.Brown@mail.walshcollege.edu

No one (0) judged this email address to have no credibility. 22 (36\%) found it to be credible and 31 (51\%) evaluated it as being extremely credible with eight faculty members having no opinion. This is by far the most credible email combining a popular and credible male name with a college email address. Using a college email address lends the most credibility to a student. A Chi-square Goodness of Fit test showed a significant difference in credibility rankings $($ Chi-sq $=37.9508, \mathrm{p}=.000)$.

Scenario Five: PartyMonster@aol.com

43 faculty members judged this individual's email address to be not credible. This is the second highest "not credible" ranking. Only seven (12\%) faculty members found it to be credible and only one ranked it as extremely credible with seven respondents having no opinion. A Chi-square Goodness of Fit test showed a significant difference in credibility rankings (Chi-sq=73.2, $\mathrm{p}=.000)$.

Scenario Six: $\underline{\text { PartyMonster@ mail.walshcollege.edu }}$

Even though the mail.walshcollege was used as the email domain, the username PartyMonster created some doubts in the faculty's mind as to this person's credibility. $45(75 \%)$ of faculty respondents evaluated this email address as not credible. Seven respondents found this email address to be credible and no one found it to be extremely credible. Seven respondents had no opinion. A Chi-square Goodness of Fit test showed a significant difference in credibility rankings $(\mathrm{Chi}-\mathrm{sq}=81.6, \mathrm{p}=.000)$.

On the basis of the results of the Chi-square Goodness of Fit tests, both hypotheses one and two were supported. Specifically, faculty perceptions of student credibility were impacted by domain name used in the email address (H1). The use of the college's email address, regardless of type of user name, was seen as more credible than any other domain name. Faculty perceptions of student credibility were impacted by the use of nicknames in the user name (H2). Nicknames were seen as far less credible than real surnames.

\section{CONCLUSION}

This project reinforced the concept that an individual's choice of email address impacts how others perceive them. Both the user and domain names impact the perception of student credibility. The email address that provides the most credibility is one that consists of the student's full name at the school domain name. The least creditable email address was found to be one that consists of a nickname at the school domain name. Students' email addresses may impact how their faculty perceives their credibility. If the email address creates a halo effect, students may find that their email address impact their credibility more in online courses than onground courses since the only point of contact with the faculty member may be through email correspondence.

It is important for students to be aware that the use of an email address may negatively impact how their faculty perceives their credibility. While many students have the ability to use a variety of email addresses, it may be in the their best interest to restrict all email correspondence with faculty to a college assigned email address that consists of some form of their name and the college domain name.

\section{AUTHOR INFORMATION}

Jeffrey A. Livermore, Ph.D., is an Associate Professor at the University of Baltimore and serves as the Director of their Undergraduate Applied Information Technology program. He is currently researching the ethics and pedagogy of teaching information technology and information security.

Linda S. Wiechowski, Ph.D., earned a bachelor degree in accounting from Walsh College. She also holds a Masters in Business Administration and a PhD in Economics, both from Wayne State University. She has been teaching finance and economics courses at Walsh College for over 20 years. Her research interests include a variety of corporate finance topics, health economics, and the integration of online technology in all levels of education. She has presented "Best Practices in Online Education" at a variety of conferences. 
Marla G. Scafe, Ph.D., has been a faculty member at Walsh College for over 25 years teaching Quantitative Methods and Research at the undergraduate, masters, and doctoral levels. She has also been a consultant-evaluator for the Higher Learning Commission of North Central Association for over 15 years. Her research interests center around the use of group testing with adult learners.

\section{REFERENCES}

1. Back, M., Schmukle, S, \& Egloff, B. (2008), How extraverted is honey.bunny77@ hotmail.de? Inferring personality from e-mail addresses. Journal of Research in Personality, 2008, doi:10.1016/j.jrp.2008.02.001.

2. Barker, H. (1926), Our leading surnames. American Speech. 1(9), 470-477.

3. Basow, S. A., Phelan, J. E., \& Capotosto, L. (2006). Gender patterns in college students' choices of their best and worst professors. Psychology of Women Quarterly, 30, 25 - 35.

4. Brunner, B., Yates, B., \& Adams, J. (2008) Mass communication and journalism faculty and their electronic communication with college students: A nationwide examination. Internet and Higher Education. 11(2), 106-11

5. Fernandez, J. \& Mateo, M. A. (1997). Student and faculty gender in ratings of university teaching quality. Sex Roles, 37, $997-1003$.

6. Glascock, J., \& Ruggiero, T. E. (2006). The relationship of ethnicity and sex to professor credibility at a culturally diverse university. Communication Education, 55, 197 - 207.

7. Livermore, J., Scafe, M., \& Wiechowski, L. (2010). Student perceptions of faculty credibility based on email addresses. American Journal of Business Education, 3(4), 27-31.

8. McGlone, E. L., \& Anderson, L. J. (1973). The dimensions of teacher credibility. The Speech Teacher, 23, $196-200$.

9. Mehrabian, A., \& Piercy, M, (1993). Differences in positive and negative connotations of nicknames and given names. The Journal of Social Psychology, 133, 737-739.

10. Morris, T., Gorham, J., Cohen, S. \& Huffman, D. (1996). Fashion in the classroom: Effects of attire on student perception of Instructors in college classes. Communication Education. 45(2), 135-148.

11. Nadler, M., \& Nadler, L. (2001). The roles of sex, empathy, and credibility in out-of-class communication between faculty and students. Women's Studies in Communication. 24(2), 241-263.

12. Newman, E., Hebein, F. \& Drost, D. (2008). The perception of an email name. International Journal of Global Business and Economics, Vol. 1, No. 1.

13. Ottolini, M, Cuzzi, S., Tender, J., Coddington, D., Focht, C., Patel, K., \& Greenbeerg, L. (2007). Decreasing variability in faculty ratings of student case presentations: A faculty development intervention focusing on reflective practice. Teaching and Learning in Medicine. 19(3), 239-24

14. Patton, T. (1999). Ethnicity and gender: An examination of its impact on instructor credibility in the university classroom. Howard Journal of Communication. 10(2), 123-144.

15. Russ, T., Simonds, C., \& Hunt, S. (2002). Coming out in the classroom...An occupational hazard?: The influence of sexual orientation on teacher credibility and perceived student learning. Communication Education. 31(3), 311-324.

16. SSA (2008, May 19). Popular Baby Names. Retrieved July, 2008 from http://www.ssa.gov/OACT/babynames/ 


\section{NOTES}

